\title{
Комплекс управления БПЛА для автоматического управления полетом
}

\author{
А.О. Лебедев, В.В. Васильев \\ Новосибирский филиал Института физики полупроводников им. А. В. Ржанова СО РАН \\ «Конструкторско-технологический институт прикладной микроэлектроники», \\ 630090, г. Новосибирск, просп. Академика Лаврентьева, 2/1 \\ тел:+7 (383) 330-65-59, эл. почта: artem_leb@mail.ru
}

DOI 10.34077/RCSP2021-156

В данной работе продемонстрирован программно-аппаратный комплекс для обеспечения автоматического полета БПЛА вдоль железной дороги без участия оператора и использования спутниковых навигационных систем.

Использование беспилотных летательных аппаратов (БПЛА) в гражданских целях стремительно расширяется в последние годы. Интерес к ним огромен. Появляются всё новые и новые, ранее

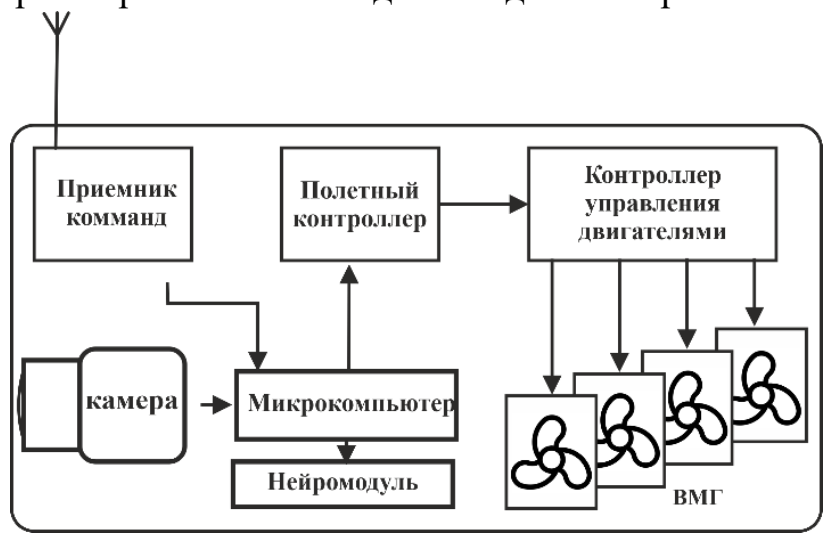

Рис. 1. Схема работы комплекса управления полётом БПЛА в автоматическом (без пилота) режиме. недоступные, области их применения. БПЛА значительно удешевляют работу, делают её более безопасной, используются для доставки товаров, техобслуживания труднодоступных объектов, как по площади, так и по высоте. Данная работа является развитием работ, начатых в [1]. Модернизированный программно-аппаратный комплекс управления БПЛА содержит микрокомпьютер Raspberry PI 4 и нейромодуль Intel Neural compute stick. Главной особенностью данного комплекса является разрыв связи между приемником команд от пульта дистанционного управление (ПДУ) и полетным контроллером. В данной схеме (Рис.1) микрокомпьютер обрабатывает кадры видеоизображения с камеры, установленной на БПЛА, определяет положение железнодорожных рельсов. Далее микрокомпьютер формирует управляющие сигналы, которые поступают на полетный контроллер и, затем, на винтомоторные группы (ВМГ).

На микрокомпьютере установлена операционная система Ubuntu, а также драйверы нейромодуля и камеры. Код программы написан на $\mathrm{C}++\mathrm{c}$ использованием библиотеки компьютерного зрения OpenCV. Обработка кадра заключается в преобразовании исходного кадра в удобный для алгоритма формат, его бинаризации и дифференцирования. Благодаря особенности железной дороги, на изображении выделяются прямые линии (рельсы). Затем применялся ПИД-регулятор ЦиглераНикольсона [2] для расчёта величины сигналов, которые подаются на полетный контроллер. Сигналы формируются таким образом, чтобы во время полёта изображения рельсов были вертикальными и находились в центре изображения. Это обеспечивает полёт БПЛА вдоль железной дороги в автоматическом режиме, без оператора и использования систем GPS или ГЛОНАСС.

В данном программно-аппаратном комплексе функция распознавания целевых объектов возложена на дополнительный специализированный микропроцессор (нейромодуль) для аппаратного ускорения работы алгоритма компьютерного зрения. В результате алгоритм выполнять корректировку полета в каждом кадре, в режиме реального времени, и обеспечивает надежный полет вдоль железной дороги в автоматическом режиме, т.е. без участия оператора-пилота. Данный режим защищен от внешних электромагнитных помех, например, при использовании средств радиоэлектронной борьбы. Также алгоритм не требует наличия специализированной квалификации оператора-пилота.

\section{Лumepamypa}

[1] A. O. Lebedev, V. V. Vasilev, B. N. Novgorodov and A. G. Paulish / Computer Vision Controlling an Autonomous Unmanned Aerial Vehicle Flight over a Railway, 2020 1st Inter. Conf. Problems of Informatics, Electronics, and Radio Engineering (PIERE), 2020, pp. 210-213.

[2] Ziegler J.G., Nichols N.B. Optimum settings for automatic controllers // Transactions of the ASME, 1942, Vol.64. pp. 759-768. 